\title{
The Estimate of Interferon-inducible Protein-10 and Interferon- $\gamma$ in Hemodialysis Patients with Chronic HCV
}

\author{
Mahmood Abdujabar Altobje ${ }^{1 *}$, Zeyad Thanoon Al-Rrassam² \\ ${ }^{1}$ Department of Biology, College of Science, University of Mosul, Mosul, Iraq; ${ }^{2}$ Department of Biophysics, College of Science, \\ University of Mosul, Mosul, Iraq
}

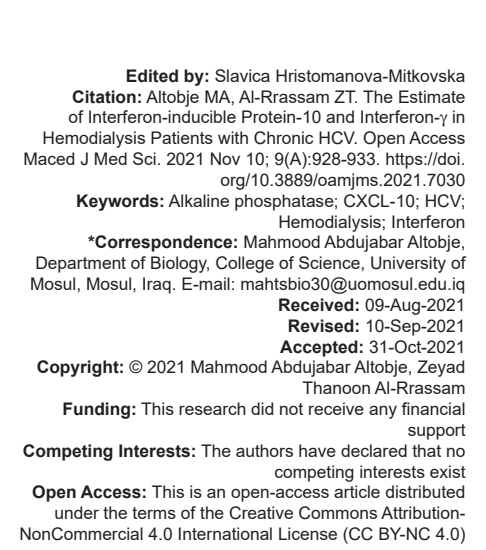

\section{Introduction}

A type of RNA virus related to the family Flaviviridae is the hepatitis $\mathrm{C}$ virus. HCV is hepatic inflammation caused by infectious disease and extreme cases contribute to elevated mortality ratings with cirrhosis and hepatocellular carcinoma. Six genotypes and roughly 50 subtypes [1] are encoded by the positive ssRNA viral genome. The key possibility of the virus being transmitted between patients with thalassemia and dialysis [2]. In the generic community, the incident rate of infection approaches $1-3 \%$, while it reaches about $3-23 \%$ in patients with hemodialysis due to viral replication by blood transfusions or using narcotic injections [3], [4]. There is no clear HCV vaccine or drug to date, with the exception of a reduction in viral load that may restrict the production of constant inflammation [5].

The mixture of a non-specific antiviral drug such as ribavirin and pegylated interferon (IFN)-alpha [6] is the starting point for the new therapy. Unfortunately, only $50 \%$ of diseases are removed by this recovery program. It was noted that the antiviral potency of IFN-gamma (IFN- $\gamma$ ) is a form of T-helper cytokine. The previous experiments have shown that IFN- $\gamma$ inhibits viral replication by mediating liver damage and has therapeutic ramifications for combination therapy [7].
A member of the chemokine family is IFN-inducible protein-10 (IP-10). In immunologically mediated pathways, IP-10 has been observed in monocytes, lymphocytes, keratinocytes, and endothelial cells. Both IFN- $\gamma$ and chemokin11 [8] are stimulated by IP-10. When IP-10 receptors bind to the CXCR3 receptors, this chemo-attractant allows the contaminated patients to increase their IP-10 levels. IP-10 plays a key role in delayed-type hypersensitivity reactions. Proinflammatory chemokine is primarily known to be an antiviral immune response for chronic hepatic cases. Virion particles can easily move through the dialysis membrane during the dialysis process and then contribute to IFN- $\alpha$ level in plasma [9], [10].

The goal of this study was to approximate the levels of IP-10 and IFN- $\gamma$ compared between two classes of patients: Receiving persistent treatment (RPT) and receiving sporadic treatment (RST) in addition to the healthy control $(\mathrm{HC})$. This research selected chronic $\mathrm{HCV}$ patients who had promising anti-HCV outcomes. In this report, 47 males and 37 females were included in the study. From July to December 2019, hemodialysis blood samples were obtained at the Central Health Laboratory, Mosul. They are between the ages of (9-67) years. The health authority of the Ethical Committee College of Medicine-University of Mosul accepted the consent patient form. The questionnaire collected 
by patients showed whether they had consistently or intermittently undergone medication.

\section{Materials and Methods}

Two combination medications were used to treat chronic cases in this study: Ribavirin and pegylated IFN-alpha. RPT group is characterized as undetected viral RNA during the 24 weeks following treatment, according to the treatment protocol. On the other hand, RST group identified as patients having not consistently obtained drugs and drugs are not always available in health centers (taken from the patient questionnaire). Most participants in the study were given pegylated IFN-alpha $2 \mathrm{~b}(1.5 \mu \mathrm{g} / \mathrm{kg} /$ week $)$ or $2 a(180 \mu \mathrm{g} /$ week) in addition to ribavirin $(1000 \mathrm{mg} /$ day) for at least 32 weeks after initiation of therapy. The ages of all participants in the study were divided into three groups: $1=(9-28 \mathrm{y}), 2=(29-48 \mathrm{y})$, and $3=(49-67 \mathrm{y})$. The samples were classified into three classes of cases: RPT (38), RST (22), and HC (24). A sample of $5 \mathrm{ml}$ of blood was obtained from each individual in the study. For the study test, the serum was isolated and frozen.

\section{Determine anti-HCV using ELISA}

The high-specificity and sensitivity Dialab package produced in Austria has been used to diagnose serum and plasma HCV antibodies in patients with chronic cases for more than 6 months.

\section{Detection of alkaline phosphatase (ALP)}

ALP is one of the catalyst enzymes known to be a criterion for the involvement of certain liver or kidney disorders. The colorimetric package relies on the hydrolysis of alkaline buffer phosphate esters using Komabiotech.

\section{IP-10 serum level estimation using ELISA}

The IP-10 ligand antigen quantification was estimated using the ELISA colorimetric package obtained from ELISA (antibodies-online, Germany). The spectrum of detection is between 8 and $500 \mathrm{pg} / \mathrm{mL}$ and was calculated by Awareness-ELISA reader, USA, under OD450 nm.

\section{Estimate serum IFN- $\gamma$ level}

Commercial human IFN- $\gamma$ ELISA Kit obtained from KOMABIOTECH, China, for the calculation of IFN- $\gamma$ was used. The detection range is between 16 and
$2000 \mathrm{pg} / \mathrm{mL}$ and was calculated by Rayto-RT ELISA Reader, Germany, under OD450 nm.

\section{Statistical analysis}

For the completion of all data analysis, the SPSS version 25 package was used. According to the Pearson statistical test, the significant similarity, homogeneity, and other statistical variants between the parameters are used to derive $p<0.01$ and $<0.05$. To draw the values graphically, Microsoft office excel version 2010 was used.

\section{Results}

In the present analysis, only dialysis patients with positive anti-HCV ELISA test results were chosen and others were omitted. Both samples were conducted to detect IP-10 and IFN- $\gamma$, including a stable monitor. Table 1 illustrates the mean, standard deviation, and standard error for both situations. Table 2 shows the statistical variants for the age pieces.

Table 1: Statistical variants of cases

\begin{tabular}{cclc}
\hline Variants & No & Mean \pm SD & SE \\
\hline IP-10 & & & \\
HC & 24 & $2.4376 \pm 4.3289$ & 0.7641 \\
RPT & 38 & $1.1551 \pm 3.4537$ & 0.4366 \\
RST & 22 & $38.3741 \pm 28.7324$ & 5.0811 \\
Total & 84 & $15.3302 \pm 25.2177$ & 2.9381 \\
IFN- $\gamma$ & & \\
HC & 24 & $11.1947 \pm 5.7120$ & 1.3722 \\
RPT & 38 & $51.0948 \pm 41.8731$ & 6.9203 \\
RST & 22 & $37.9377 \pm 27.1200$ & 6.2872 \\
Total & 84 & $38.4276 \pm 38.5034$ & 3.8593 \\
ALP & & & \\
HC & 24 & $1.392 E 2 \pm 56.2501$ & 10.6902 \\
SVR & 38 & $2.356 E 2 \pm 125.1218$ & 20.5298 \\
RIT & 22 & $3.845 E 2 \pm 172.5600$ & 35.4325 \\
Total & 84 & $2.541 E 2 \pm 158.3599$ & 15.1820 \\
\hline IP-10: Inducible protein-10, IFN- $-\gamma$ : Interferon-gamma, ALP: Alkaline phosphatase, HC: Healthy control, RPT: \\
Receiving persistent treatment, RST: Receiving sporadic treatment. & \\
& & &
\end{tabular}

Compared to the $\mathrm{HC}$ population, which was beyond the usual range, the ALP level demonstrated a larger rise in the RPT patient group than in the RST group. The significant ALP value indicates a coefficient of status classes at $p<0.01$, (Figure 1). ALP correlation level with sex or age groups was inconsiderable under the value with $p>0.05$, (Figures 2 and 3), respectively.

Table 2: Statistical variants on to age sections

\begin{tabular}{lcll}
\hline Variants & No & Mean \pm SD & SE \\
\hline IP-10 & & & \\
$9-28$ y & 30 & $21.1328 \pm 31.2898$ & 5.8760 \\
$29-48$ y & 37 & $8.3791 \pm 16.6911$ & 3.0888 \\
49-67 y & 17 & $21.3005 \pm 22.7209$ & 6.3386 \\
Total & 84 & $12.3598 \pm 24.2818$ & 2.3512 \\
IFN- $\gamma$ & & & \\
$9-28$ y & 30 & $32.7343 \pm 24.7109$ & 4.7812 \\
$29-48$ y & 37 & $42.9082 \pm 41.6779$ & 6.8009 \\
49-67 y & 17 & $21.0162 \pm 35.7123$ & 8.1650 \\
Total & 84 & $35.4540 \pm 36.5493$ & 2.9879 \\
ALP & & & \\
$9-28$ y & 30 & $2.587 E 2 \pm 152.5180$ & 27.6705 \\
$29-48$ y & 37 & $2.837 E 2 \pm 162.0202$ & 24.6461 \\
49-67 y & 17 & $2.924 E 2 \pm 141.8372$ & 30.8601 \\
Total & 84 & $2.4166 E 2 \pm 147.3597$ & 15.1683 \\
\hline IP-10: Inducible protein-10, IFN- $\gamma:$ Interferon-gamma, ALP: Alkaline phosphatase. &
\end{tabular}




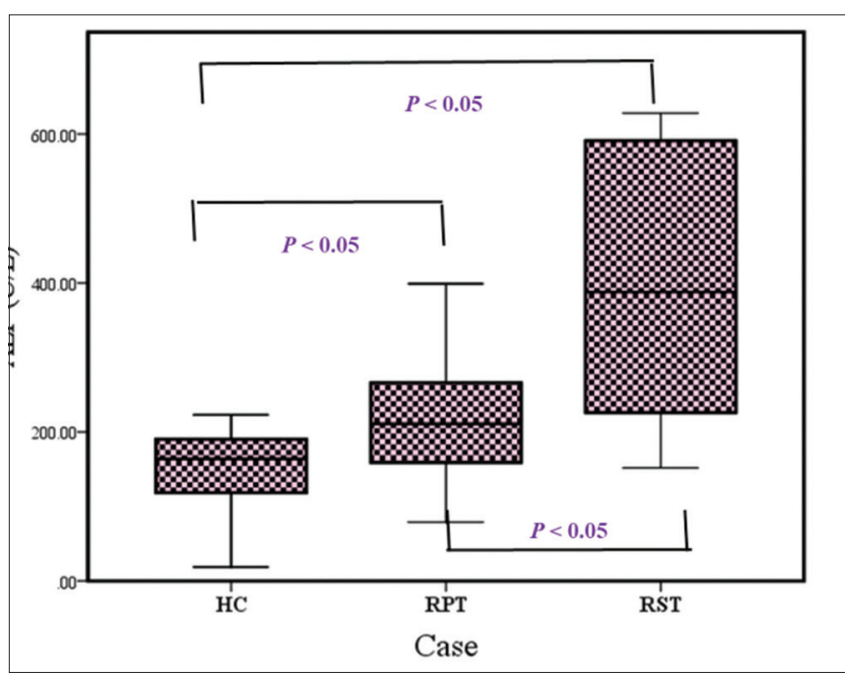

Figure 1: ALP (U/L) level versus three groups of cases. ALP: Alkaline phosphatase

In the RST group, the IP-10 serum level was prevalent whereas it was within the usual range for the $\mathrm{HC}$ and RPT categories. At $\mathrm{p}<0.01$ on Pearson test, the relevant association found here was significant.

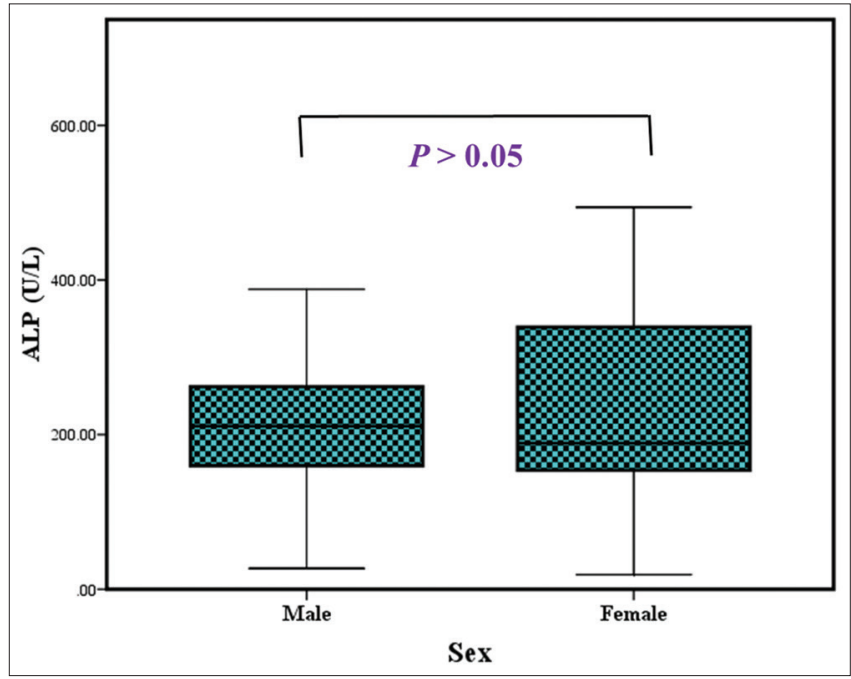

Figure 2: ALP level versus sex groups. ALP: Alkaline phosphatase

There is also a correlation of $p<0.05$ between the (HC-RST) and (RPT-RST) groups [4]. There is only no correlation between the (HC-RPT) classes, but also between the

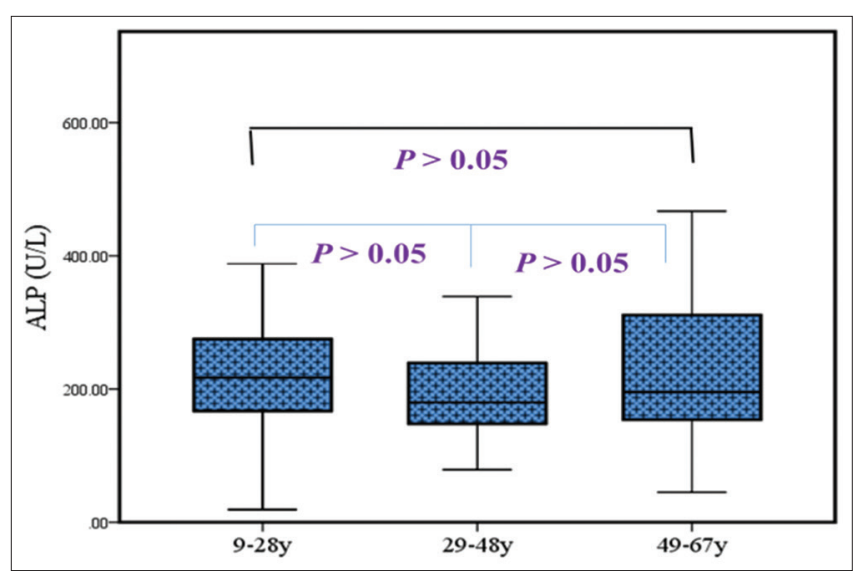

Figure 3: ALP level versus age groups. ALP: Alkaline phosphatase

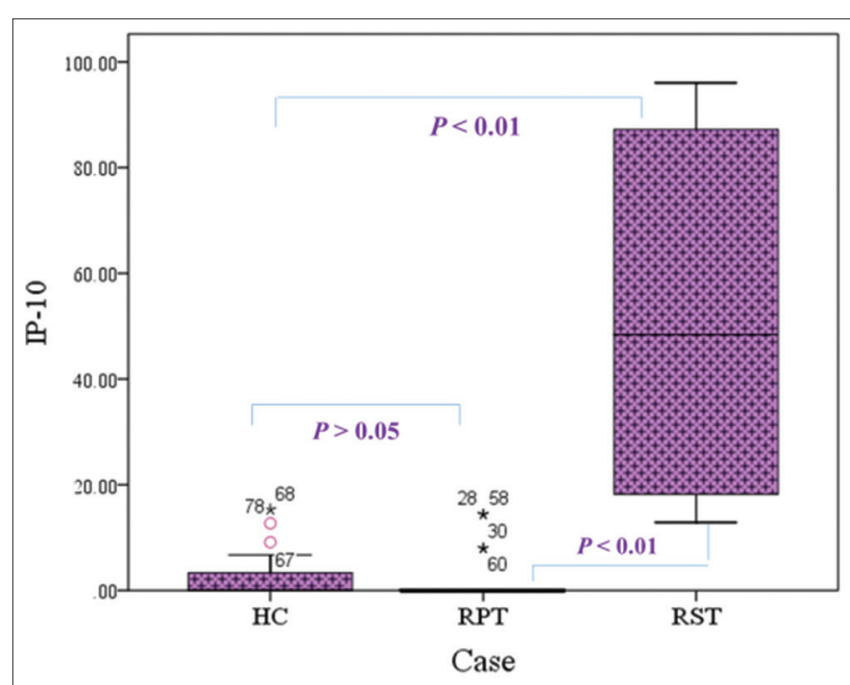

Figure 4: IP-10 (pg/ml) level versus case groups. IP-10: Inducible protein-10

IP-10 age group and the sex group seen in Figures 4-6 with $p>0.05$ value.

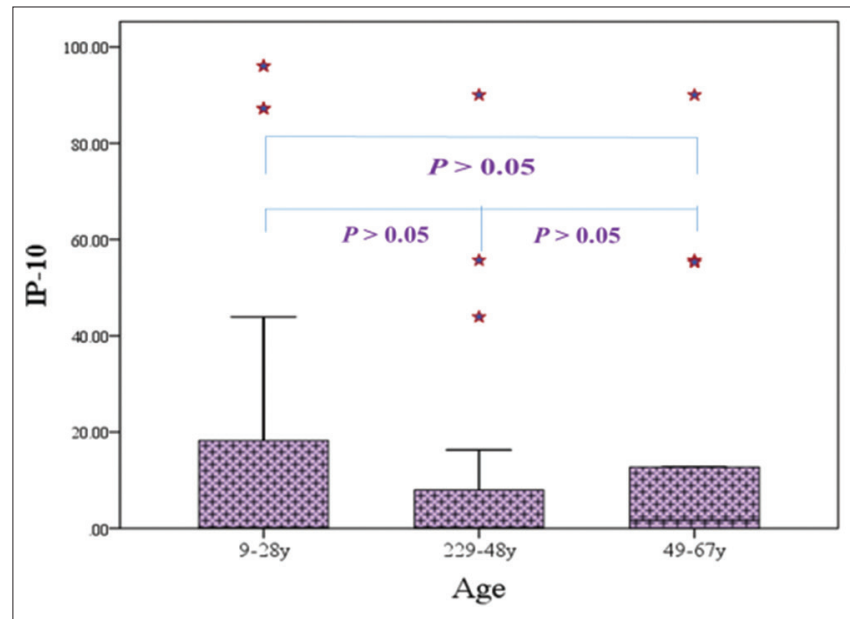

Figure 5: IP-10 level versus age groups. : Extreme outcome values. IP-10: Inducible protein-10

In the RPT and RST groups, but without the $\mathrm{HC}$ group with a large detection value, high serum IFN levels were seen [7]. The important value was observed between (HC-RPT) and (HC-RST) classes,

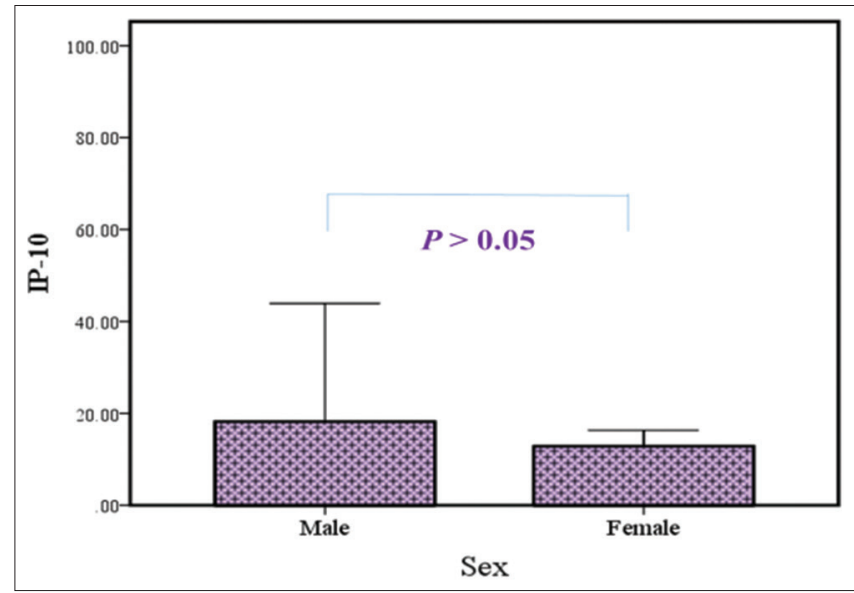

Figure 6: IP-10 level versus sex groups. IP-10: Inducible protein-10 
while on the contrary, no association was observed between (RPT-RST), genders, and age groups at all, (Figures 7-9). The coefficient of association between the parameters under analysis is shown in Table 3.

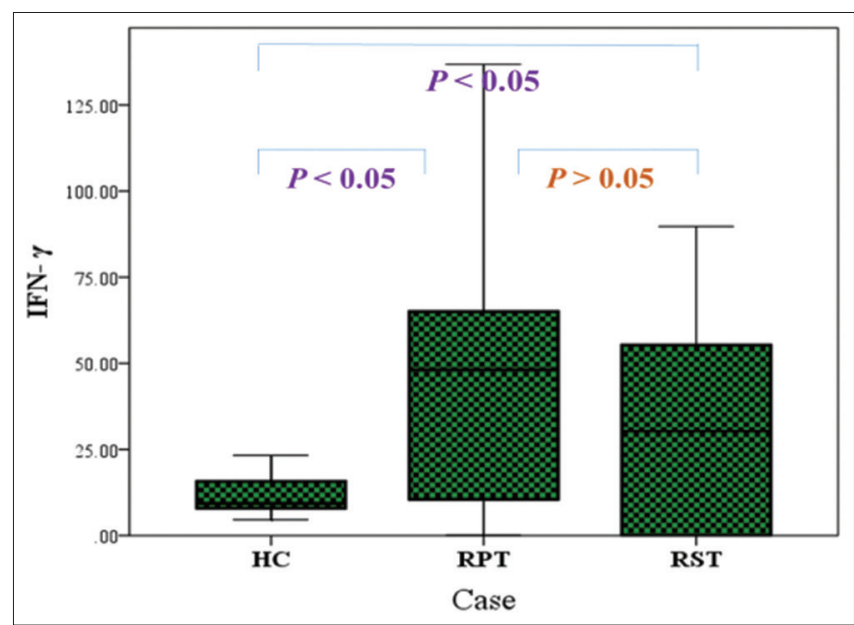

Figure 7: IFN- $\gamma(\mathrm{pg} / \mathrm{ml})$ serum levels versus cases groups. IFN- $\gamma$ : Interferon-gamma

\section{Discussion}

With the latest research update, the number of $\mathrm{HCV}$ infected individuals has reached approximately 175 million worldwide. While the number of infections has been increased, different forms of cytokines are involved as a response against multiple viral diseases in the immune system. The key problem, therefore, occurs particularly for hemodialysis and thalassemia patients with HCV due to the ease of transmission of virion particles through the dialysis process [11], [12].

The assessment level of IFN IP-10, IFN- $\gamma$, and ALP in serum dialysis patients was performed in the present study. These patients are used to constant

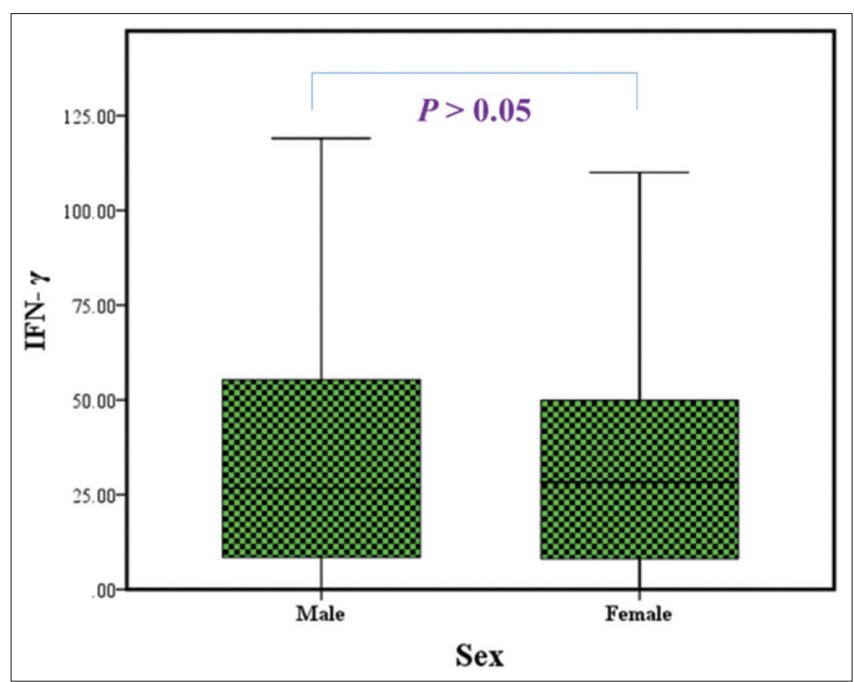

Figure 8: IFN-y serum levels versus sex groups. IFN- $y$ : Interferon-gamma or sporadic use of pegylated IFN- $\alpha$ and ribavirin combination medicines for more than 6 months. Due to the lack of supply of one or both medications in health facilities yearly, the RST community provides occasional drugs. The viral RNA in the serum was low-loaded (data not registered). It has been noted that with the viral load in viremia, the IP-10 level decreases [13], [14].

Important correlations were made between variables under analysis in our results. In general, a coefficient of concern between case classes, including health control and variables, was found. On the opposite, the factors are not associated with age and gender classes. The predicted parameter elevation was observed in intermittent therapy groups receiving IP-10, IFN- $\gamma$, and ALP. Due to the elevation of cytokines during the infected stage, persistent treatment groups reported an improvement in the IP-10 and IFN- $\gamma$ levels, with a standard range of ALP studies. The predictable findings are due to the theory that the frequency of the majority of proteins returns to the chronic cases' normal range.

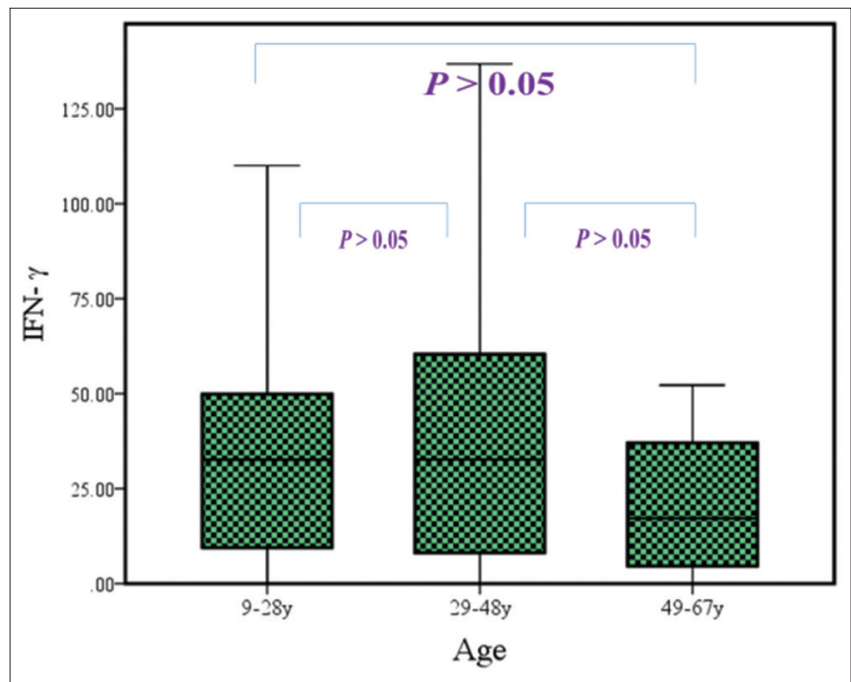

Figure 9: IFN-y serum levels versus age groups. IFN- $y$ Interferon-gamma

Our data show that the degree of $\mathrm{IP}-10$ is known to be the key indicator for differentiating between patients with HCV who are undergoing constant or sporadic care. Some researches agreed with our results that the interleukins: $2,4.8,10$, IP-10, and IFN- $\gamma$ were increased relative to RPT in the RST community. The IP-10 level was found in a sample as a predictor of liver fibrosis. Other tests also revealed that the IP-10 baseline provides proof of medication failure [15]. Besides, in the RPT community, the viral load varies from $50 \%$ while taking combination drugs [16].

Table 3: Correlation coefficient between variables with mean differences

\begin{tabular}{llll}
\hline Dependent variable & Case type & Mean differences & Sig. \\
\hline ALP & HC RPT & $85.4845^{*}$ & 0.003 \\
& HC RST & $230.0256^{*}$ & 0.000 \\
& RST RPT & $162.5495^{*}$ & 0.005 \\
IFN- $\gamma$ & HC RPT & $37.9402^{*}$ & 0.000 \\
\hline ALP: Alkaline phosphatase, IFN- $\gamma$ : Interferon-gamma, HC: Healthy control, RPT: Receiving persistent
\end{tabular}
treatment, RST: Receiving sporadic treatment. 
A clinical trial found that in patients with RST, the IP-10 level in RPT was substantially lower [17]. This outcome coincides with our results.

Compared to the $\mathrm{HC}$ group, the IFN- $\gamma$ level was elevated without any corresponding meaning in both the RPT and RST categories. This outcome may be due to a virus attack by the immune system. It is understood that according to studies performed on mouse serum, IFN- $\alpha$ and IFN- $\gamma$ play a key role as antiviral agents. Such a previous report agrees with our evidence that in chronic hepatitis $C$ patients who have taken combination medications and IFN- $\gamma$ elevates [18].

In addition, a study found that IP-10 is activated by IFN- $\gamma$ in patients who have taken combination drugs intermittently [19], [20]. Our findings revealed that the amount of ALP serum does not affect patients with hemodialysis, while association identification with case groups was found.

Our analysis, like any research, has some limitations. To predict the amount of IP-10 during and after therapy, there is no follow-up. The follow-up of patients is among the dilemmas and it is not encouraging to advise them to perform exams immediately, in addition to the percentage of patients who respond to these lengthy procedures.

\section{Conclusions}

Because of the rise in the number of deaths, the hepatitis $C$ virus remains a public health concern around the world. In the present research, immunological parameters were measured in chronic hemodialysis patients after more than 6 months of drug administration. The IP-10 serum level can be a warning primarily for patients who have administered a mixture of medications intermittently. In both the RPT and RST cohorts, IFN- $\gamma$ serum levels are usually elevated. Serum level ALP is not a particular chronic HCV predictor.

\section{Acknowledgments}

We would like to thank the Central Health Laboratory for supplying blood samples after this report. For recording this work, we thank the University of Mosul.

\section{References}

1. Lu MY, Huang $\mathrm{Cl}$, Dai1CY, Wang SC, Hsieh MY, Hsieh MH, et al. Elevated on-treatment levels of serum IFN-gamma is associated with treatment failure of peginterferon plus ribavirin therapy for chronic hepatitis C. Sci Rep. 2016;6:22995.

PMid:26965318

2. Etik D, Ocal S, Boyacioglu A. Hepatitis $C$ infection in hemodialysis patients: A review. Hepatology. 2015;7(6):885-95. https://doi.org/10.4254/wjh.v7.i6.885 PMid:25937865

3. Vigani A, Pavan M, Tozzo R, Gonçales E, Lazarini M, Oliveira A, Gonçales F. Extended treatment with interferon and ribavirin in a hemodialysis patient with chronic hepatitis C. Case Report. 2009;21:93-5. https://doi.org/10.4254/wjh.v7.i6.885

4. Yu YC, Wang $Y$, He CL, Wang MR, Wang YM. Management of hepatitis $C$ virus infection in hemodialysis patients. Hepatology. 2014;6(6):419-25. https://doi.org/10.4254/wjh.v6.i6.419 PMid:25018852

5. Brownell J, Polyak S. Molecular pathways: Hepatitis C virus, CXCL10, and the inflammatory road to liver cancer. Clin Cancer Res. 2013;19(6):1347-52. https://doi.org/10.1371/journal. pone.0023856

PMid:23322900

6. Tsuge M, Fujimoto Y, Hiraga N, Zhang Y, Ohnishi M, Kohno T, et al. Hepatitis $C$ virus infection suppresses the interferon response in the liver of the human hepatocyte chimeric mouse. Plos One. 2011;6(8):e23856. https://doi.org/10.4254/wjh.v6.i6.419 PMid:21886832

7. Barakat A, Hegazy A, Farag R, Abdul Baky A, Arafa L, Farouk A Role of interferon-gamma and immune response biomarkers in predicting IFN-alpha responsiveness and treatment outcome in patients with Hepatitis C virus. Int J Virol. 2012;8(4):288-98. https://doi.org/10.1172/JCl40594

8. Casrouge A, Decalf J, Ahloulay M, Lababidi C, Mansour H, Vallet-Pichard A, et al. Evidence for an antagonist form of the chemokine CXCL10 in patients chronically infected with HCV. J Clin Investigation. 2011;121(1):308-17. https://doi. org/10.1172/JCl40594

PMid:21183794

9. Mascia C, Vita S, Zuccalà P, Marocco R, Tieghi T, Savinelli S, et al. Changes in inflammatory biomarkers in HCV infected patients undergoing direct-acting antiviral-containing regimens with or without interferon. PLoS One. 2011;3:1-14. https://doi. org/10.1002/hep.21011

10. Miyaki E, Hiraga N, Imamura M, Uchida T, Kan H, Tsuge M, et al. Interferon-alpha treatment stimulates interferon-gamma expression in Type I NKT cells and enhances their antiviral effect against Hepatitis C virus. PLoS One. 2017;2:1-2. https:// doi.org/10.1016/j.ekir.2017.04.003

PMid:28253324

11. Caragea D, Mihaliovici A, Streba C, Schenker M, Ungureanu B, Caragea I, et al. Hepatitis C infection in hemodialysis patients. Curr Health Sci J. 2017;44(2):107-12. https://doi.org/10.1371/ journal.pone. 0172412 PMid:30746156

12. Romero Al, Lagging $M$, Westin J, Dhillon AP, Dustin LB Pawlotsky JM. Interferon (IFN)-gamma inducible protein-10: Association with histological results, viral kinetics, and outcome during treatment with pegylated IFN-alpha $2 \mathrm{a}$ and ribavirin for chronic Hepatitis C virus infection. J Infect Dis. 2006;194(7):895903. https://doi.org/10.1086/507307 PMid:16960776

13. Omran D, Hamdy S, Tawfik S, Esmat S, Saleh D, Zayed R Association of Interferon- $\gamma$ inducible protein-10 pretreatment level and sustained virological response in HCV-positive Egyptian patients. Ann Clin Lab Sci. 2014;44(2):167-72. PMid:24795055

14. Crisan D, Grigorescu M, Radu C, Suciu A, Grigorescu M. 
Interferon- $\gamma$-inducible protein-10 in chronic Hepatitis C: Correlations with insulin resistance, histological features and sustained virological response. Indian J Med Res. 2017;145(4):543-50. https://doi.org/10.4103/ijmr. IJMR_1410_14

PMid:28862188

15. Huang $\mathrm{Y}$, Chen $\mathrm{X}$, Konduri $\mathrm{M}$, Fomina $\mathrm{N}$, Lu J, Jin $\mathrm{L}$, et al Mechanistic link between the anti-HCV effect of interferon gamma and control of viral replication by a Ras-MAPK signaling cascade. Hepatology. 2006;43(1):81-90. https://doi. org/10.1002/hep.21011

PMid: 16374867

16. Shin EC, Protzer U, Untergasser A, Feinstone S, Rice S, Hasselschwert $\mathrm{D}$, et al. Liver-directed gamma interferon gene delivery in chronic Hepatitis C. J Virol. 2005;79(21):13412-20. https://doi.org/10.1128/JVI.79.21.13412-13420.2005
PMid:16227262

17. Khedmat $H$, Amini M, Ghamar-Chehreh M, Agah S. Hepatitis $C$ virus infection in dialysis patients. Saudi J Kidney Dis Transpl. 2014;25(1):1-8. https://doi.org/10.4103/1319-2442.124455 PMid:24434375

18. Agarwal S, Bagchi S, Yadav R. Hemodialysis patients treated for Hepatitis C using a sofosbuvir-based regimen. Kidney Int Rep. 2017;2(5):831-5. https://doi.org/10.1016/j.ekir.2017.04.003 PMid:29270489

19. Dawood A, Khaleel A, Hayawi A. Estimate viral RNA of hepatitis C of $\beta$-thalassemia patients in Nineveh province. EJMCM. 2020;7(10):1-8

20. Dawood A, Altobje M, Al-Rrassam Z. Adoption of Euvax-B vaccine in Nineveh. VacciMonitor. 2021;30(2):91-5. 